\title{
Confined and unconfined nucleate boiling of HFE7100 in the presence of nanostructured surfaces
}

\author{
R.R. Souza ${ }^{\mathrm{a}}$, E.M. Cardoso ${ }^{\mathrm{b}}$, J.C. Passos ${ }^{\mathrm{a}, *}$ \\ a Department of Mechanical Engineering, LEPTEN - Laboratory of Process Engineering and Energy Technology, Federal University of Santa Catarina, 88010-900 \\ Florianópolis, SC, Brazil \\ ${ }^{\mathrm{b}}$ UNESP - Univ Estadual Paulista, Department of Mechanical Engineering, Av. Brasil Centro, 56, 15385-000 Ilha Solteira, SP, Brazil
}

\section{A R T I C L E I N F O}

\section{Keywords:}

Confined nucleate boiling

Nanoparticle size

Surface roughness

Heat transfer coefficient

\begin{abstract}
A B S T R A C T
This article presents experimental results for the confined and unconfined nucleate boiling of saturated HFE7100 $\left(\mathrm{C}_{4} \mathrm{~F}_{9} \mathrm{OCH}_{3}\right)$ at atmospheric pressure and using nanostructured copper discs as heating surfaces. The nanostructures studied consisted of nanoparticles of maghemite $\left(\mathrm{Fe}_{2} \mathrm{O}_{3}\right)$ on the heating surface, comprised of a copper disc. Different values for the diameter $(10$ and $80 \mathrm{~nm})$ and roughness $\left(R_{a}=0.02 \mu \mathrm{m}\right.$ and $\left.0.16 \mu \mathrm{m}\right)$ were studied. The nanoparticle adhesion on the heating surface plays a more important role in the confined boiling process than the surface roughness. As an original result, it was demonstrated that for a confinement with a gap length of $0.1 \mathrm{~mm}$ and heat flux of $40 \mathrm{~kW} / \mathrm{m}^{2}$ the heat transfer coefficient (HTC) increased by $31 \%$ and $100 \%$ for the cases with the deposition of nanoparticles of $10 \mathrm{~nm}$ and $80 \mathrm{~nm}$, respectively. However, without the nanoparticles the HTC decreased by $21 \%$ when compared with the reference case, that is, a smooth plate $\left(R_{a}=0.02 \mu \mathrm{m}\right)$ and unconfined boiling.
\end{abstract}

\section{Introduction}

The nucleate boiling regime can be considered one of the most effective ways to obtain a higher heat flux and a relatively small difference between the wall temperature and the saturation temperature of the liquid. In the literature, few of the studies carried out focus on the physics of the boiling phenomenon. Wang and Dhir [1] evaluated the effect of surface wettability on the heat transfer during the water nucleate boiling regime and they drew attention to the following parameters: nucleation site density and the spatial distribution (distance between active nucleation sites and their neighborhood). According to these authors, these parameters are strongly dependent on the type of finishing and/or surface treatment. Rougher surfaces were found to be associated with a higher HTC due to the increased number of nucleation sites, and this result was also reported by other authors (Mikic and Rohsenow [2], Berenson [3], Kang [4]). The heat transfer mechanism may be related to the number of vapor bubbles present on the heating surface, and the general trend is that the HTC decreases as the wettability increases (Dhir [5]).

Surface roughness also has a significant impact on the boiling process. Pool boiling on heating surfaces with different roughness values, at atmospheric pressure using two working fluids with different wetting characteristics, was experimentally studied by Jones et al. [6]. For water, the results showed a slight improvement in the HTC for roughness values higher than $R_{a}=1.08 \mu \mathrm{m}$. A different trend was found for FC 77: the heat transfer coefficient continuously increased with the surface roughness, for the same heat flux value. The general trend was correlated using $h=R_{a}^{m}$, where $m$ is the roughness exponent. The results indicated a stronger dependence on the surface roughness for FC 77 with $m=0.2$ compared to $m=0.1$ for water.

The majority of models relating boiling heat transfer to nucleation site density suggest that the nucleation site density and the wall superheating are correlated by a power law, represented by (Wallis [7]): $q^{\prime \prime}=\left(n_{a}^{\prime}\right)^{x} \cdot\left(T_{w}-T_{\text {sat }}\right)^{y}$

where $n_{a}^{\prime},\left(T_{w}-T_{\text {sat }}\right), x$ and $y$ are, respectively, the nucleation sites density, the wall superheating, and the exponents. The value for the exponent $x$ varies between 0.3 and 0.5 while $y$ varies between 1.0 and 1.8, as suggested by classical models (Mehta and Khandekar, [8]).

McHale and Garimella [9] emphasized that most of the published studies on boiling have considered idealized surfaces in their models, that is, they are totally smooth with perfectly conical or reentrant cavities, among other features, while surfaces with more natural structures have not been extensively studied.

Another difficulty highlighted by Dhir [10] and Avedisian [11] is to connect the micro and nanoscales in research on boiling mechanisms.

\footnotetext{
* Corresponding author

E-mail address: julio.passos@ufsc.br (J.C. Passos).
} 


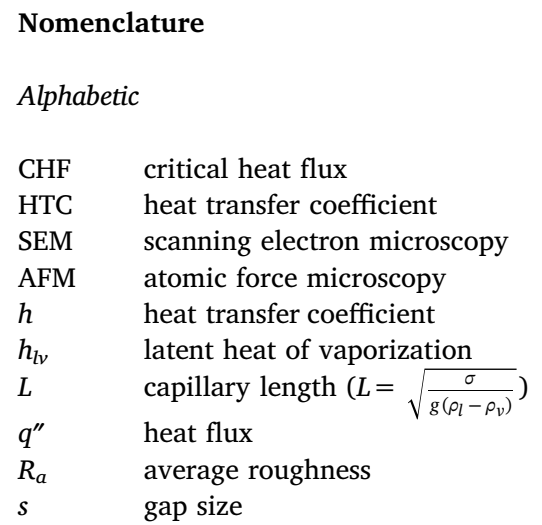

$T_{\text {sat }} \quad$ saturation temperature of the fluid

$T_{w} \quad$ surface temperature
Greek letters

$\begin{array}{ll}\rho & \text { density } \\ \sigma & \text { surface tension } \\ v & \text { specific volume }\end{array}$

Subscripts

$\begin{array}{ll}l & \text { liquid } \\ v & \text { vapor }\end{array}$
Recent studies focused on the effect of nanostructures and nanofluids on the nucleate boiling regime have shown that the behavior of the boiling process is very sensitive to changes in the surface characteristics, especially the number and shape of nucleation sites (Wen [12], Shahmoradi et al. [13]).

The deposition of nanoparticles on the heating surface increases the surface roughness and the wettability, and the critical heat flux (CHF) can be significantly improved. Rainho Neto et al. [14] measured the HTC and the CHF during the nucleate boiling of water in the presence of nanoparticles of alumina, maghemite and carbon nanotubes (CNTs). They showed that the CHF increased by $26-37 \%$ for all tests when compared with the reference case for water. The heat transfer coefficients were almost the same with the deposition of CNTs on the copper plate and lower for the other two nanoparticles, when compared with the reference case (copper in water as the base fluid).

Concerning the heat transfer coefficient, most researchers reported no change in the HTC, others observed a deterioration in the heat transfer (Kim and Kim [15], Bang and Chang [16], Kwark et al. [17]) and some authors have reported heat transfer enhancements (Kedzierski [18], White et al. [19], Heitich et al. [20]). Nevertheless, authors generally agree that a CHF enhancement can be achieved, despite of the differences in the percentage reported (from $10 \%$ to $400 \%$ ). Both the heat transfer coefficient and critical heat flux modifications can be attributed, mainly, to changes in the surface wettability due to the nanoparticles deposition.

Mehta and Khandekar [8] suggested that the density of active nucleation sites, $n_{a}^{\prime}$, can be affected by two mechanisms: (i) physical adhesion, blocking the active nucleation sites with nanoparticles and also reducing the radius of the cavities present on the heating surface; and (ii) a change in the contact angle/wetting characteristics due to the addition of nanoparticles in the base fluid. According to the authors, nanoparticle deposition could reduce the cavity radius, leading to a decrease in the HTC.

The effect of nanostructured surfaces on heat transfer has been experimentally observed in recent studies by Jun et al. [21], Tang et al. [22] and Lee et al. [23]. According to these authors, nanostructured surfaces have the potential to alter the surface properties, such as, wettability and thermal conductivity.

Narayan et al. [24] carried out experiments to investigate the effects of the nanoparticle concentration, surface roughness and nanoparticle size on pool boiling heat transfer on a vertical tubular heater using water as the base fluid. Different heating surface roughness values (48, 98 and $524 \mathrm{~nm}$ ) and alumina nanoparticle concentrations (0.5, 1 and $2 \mathrm{wt} \%)$ were analyzed. The results showed an enhancement or deterioration in the HTC depending on the combination of nanoparticle concentration, surface roughness and nanoparticle size. The authors introduced a surface interaction parameter (SIP), which is defined as the ratio between the surface roughness $R_{a}$ and the particle size $d_{p}$, to take into account the heating surface characteristics and its interaction with the nanoparticles deposited on it.

Ji et al. [25] studied boiling heat transfer surfaces with uniform and non-uniform porous coatings using acetone as the working fluid, at atmospheric pressure, on different heating surfaces including a plain surface and surfaces with a thick porous coating with uniform particle layer thickness or with 2-D and 3-D porous coatings. In general, the authors observed that the 2-D and 3-D porous coatings significantly enhanced the pool boiling heat transfer and their explanation was based on the effects of the porous structure on liquid suction and the valley channel on vapor escape. According to Ji et al. [25], these effects are dependent on the solid and liquid thermophysical properties, the pore parameters, such as pore size and distribution, and the porous layer thickness.

Kim et al. [26] proposed a novel mechanism for HTC reduction and $\mathrm{CHF}$ enhancement using nanofluids $\left(\mathrm{Al}_{2} \mathrm{O}_{3}\right.$ /water nanofluids). Below a critical concentration ( $0.001 \mathrm{vol} \%$ in this study), the CHF increases while the HTC decreases with increasing nanoparticle concentration. Above the critical concentration, both the CHF and HTC decrease with increasing nanoparticle concentration. According to the authors, this is because below the critical concentration the effective surface area increases and above the critical concentration the film resistance increases, blocking the cavities.

Souza et al. [27] presented experimental results for HFE $7100 \mathrm{nu}-$ cleate boiling on copper discs, nanostructured with maghemite $(10 \mathrm{~nm}$ and $80 \mathrm{~nm}$ diameters) using the nanofluid evaporation technique. The surface roughness $\left(R_{a}\right)$ was $0.16 \mu \mathrm{m}$ before the nanoparticle deposition. The authors concluded that the microstructure of the nanostructured surfaces influences the heat transfer process in such a way that the surface defects can be treated as nucleation sites. Also, factors such as the size and quantity of these defects are important.

In several industrial applications where an immersion-cooling system is used it is very common that the space reserved for the vaporliquid system is small. In these situations, after the formation and growth of vapor bubbles, bubble deformation can occurs and the time for which the vapor bubble remains in the limited space increases. When this occurs, the nucleate boiling process shows a different behavior in relation to the heat transfer (Ishibashi and Nishikawa [28], Katto et al. [29], Passos et al. [30], Cardoso and Passos [31] and Cardoso et al., [32]).

The effect of the gap size on the bubbles can be characterized by a dimensionless parameter known as the Bond number, Bo, defined as the ratio of the gap, $s$, between the heating surface and the unheated surface, and the capillary length, $L=\sqrt{\frac{\sigma}{g\left(\rho_{l}-\rho_{v}\right)}}$,

$B o=\frac{s}{\sqrt{\frac{\sigma}{g\left(\rho_{l}-\rho_{v}\right)}}}$

where $\sigma, g, \rho_{l}$ and $\rho_{v}$ represent the surface tension, the acceleration due to gravity, the liquid density and the vapor density, respectively. As 
demonstrated in $[28,32]$, for $B o<1$ there is a gap size effect and the bubbles tend to be coalesced and deformed, while for $B o>1$ the bubbles become isolated.

The characteristic most commonly observed is that the HTC increases when the confinement increases, which means a decrease in the distance between the heating and the non-heating surfaces, for low and moderate heat fluxes [28-32]. However, with an increase in the heat flux, the vapor bubbles grow rapidly in the gap region and a large mass of vapor is formed which can reduce the cooling effect of the working fluid because the contact between the fresh liquid front and the heating surface is restricted, leading to a reduction in the heat transfer.

Yang and Liu [33] analyzed five microporous surface coatings with thicknesses of $81,109,150,182$ and $225 \mu \mathrm{m}$, in confined and unconfined spaces. The microporous coating consisted of aluminum particles with diameters ranging from 11 to $38 \mu \mathrm{m}$, mixed with OB-200 and methyl-ethyl-ketone (MEK). The authors concluded that for surfaces with microporous coatings the HTC is affected by the (a) number of active nucleation sites, (b) bubble residence time on the heated surface and (c) changes in the thermal resistance of the microporous coating layer. For confined nucleate boiling, the unheated surface hindered the vapor from leaving the heating surface, leading to an increase in the wall superheating and, consequently, a decrease in the heat transfer performance.

The above review summarizes classical and recent results related to the effect of the surface roughness on the nucleate boiling HTC. Modifying the surface roughness can cause an inversion of the results, depending on the combination of the surface roughness and the diameter of the nanoparticles deposited on the surface. A second important point of this review was the effect of the modification of the heat transfer mechanism on nucleate boiling when the confinement conditions reduce the space available for the liquid and vapor, allowing an increase or a decrease in the HTC depending on the heat flux.

The aim of this study is to complement the work of Souza et al. [27], who studied the saturated nucleate boiling heat transfer of HFE 7100 on a copper surface with different roughness values due to the presence of maghemite nanoparticles of two diameters, 10 and $80 \mathrm{~nm}$. New results were obtained from tests on three kind of surfaces, a smooth heating surface, with $R_{a}=0.02 \mu \mathrm{m}$, and two new nanostructures formed by the deposition of maghemite nanoparticles of two diameters, 10 and $80 \mathrm{~nm}$, under confined or unconfined conditions. The values reported herein are compared with the results presented in [27], where the reference copper surface had a greater degree of roughness, $R_{a}=0.16 \mu \mathrm{m}$. These results can aid the design of new equipment with space restrictions or in cases where the operational principle is based on flow boiling in microchannels.

\section{Experiment}

Fig. 1 shows a schematic of the experimental apparatus developed to perform the tests, see also Souza et al. [27]. The boiling chamber is installed in the center of an external chamber, both assembled between two horizontal AISI 316 plates. The boiling chamber is a vertical glass tube, which contains the test section with the working fluid inside. The required degree of tightness is obtained with insulating rubber and vacuum grease. The temperature of the working fluid is imposed by a forced flow of water in the space between the glass tube of the boiling chamber and the wall of the external chamber. Inside the boiling chamber, in the upper part, there is a coil condenser cooled by water, whose temperature is controlled by a second cryostat. A pressure transducer measures the pressure inside the boiling chamber and a valve is used to charge the working fluid.

The thin gap between the periphery of the copper disc and the PVC support is filled with Araldite ${ }^{\circledast}$ epoxy resin but this is not enough to avoid the presence of natural parasite sites at the periphery of the copper disc. Moreover, the polishing treatment applied to the copper surface, after the boiling tests, can contribute to creating new parasite nucleation sites. This can adversely affect the quality of the experimental results.

The test section consists of a copper disc of $12 \mathrm{~mm}$ diameter and $1 \mathrm{~mm}$ thickness, with three type-E thermocouples of $0.15 \mathrm{~mm}$ diameter set in the disc close to its center. The copper disc is heated by a $6.4 \Omega$ electrical resistance skin heater fixed by Araldite ${ }^{\circledR}$ epoxy resin onto the bottom side of the disc. This disc is fixed to a piece of PVC beveled to an angle of $45^{\circ}$ with an outside diameter of $20 \mathrm{~mm}$, as shown in Fig. 2.

The experiments were performed using $\mathrm{HFE7100}\left(\mathrm{C}_{4} \mathrm{~F}_{9} \mathrm{OCH}_{3}\right)$, fabricated by $3 \mathrm{M}^{\mathrm{TM}}$ Novec $^{\mathrm{TM}}$, as the working fluid under saturated conditions at $p=1 \mathrm{bar}\left(T_{\text {sat }}=61{ }^{\circ} \mathrm{C}\right)$. HFE7100 is a dielectric liquid that allows direct contact with the electronic components through immersion. The surface of the copper disc, which is in contact with the working fluid, was polished using \#600 or \#1200 emery paper, corresponding to roughness $\left(R_{a}\right)$ values of $0.16 \mu \mathrm{m}$ and $0.02 \mu \mathrm{m}$, respectively. The confining element, shown in Fig. 2, consists of a transparent acrylic piece fixed to an aluminum support and this, in turn, is fitted to the test section. This conical unheated plate is placed parallel to the heating surface $\left(45^{\circ}\right.$ cone angle and $12 \mathrm{~mm}$ diameter at the bottom). Gap sizes of 0.1 and $13 \mathrm{~mm}$ were analyzed in this study, corresponding to Bond number equal to 0.09 (confined case, $B o<1$ ) and 11.8 (unconfined case, $B o>1$ ), respectively. The capillary length is close to $1.1 \mathrm{~mm}$.

The DC power supply HP6030A is connected to the skin heater and controlled by a PC using LABVIEW. The experimental procedure was kept consistent in order to ensure the repeatability of the results. The heating of the copper disc is controlled by increasing the heat flux.

The temperature uncertainty was $\pm 0.8^{\circ} \mathrm{C}$. The experimental uncertainty for the heat flux varied from $2 \%$ to $6 \%$ for all surfaces tested. The experimental uncertainty for the heat transfer coefficients varied from $1.7 \%$ to $11 \%$, for the substrates without deposition and with a nanostructured surface.

\subsection{Test section preparation}

In this study, six types of heating surface were analyzed (see Table 1). All surfaces were initially polished using emery paper \#600 (rough surface) or \#1200 (smooth surface), corresponding to roughness $\left(R_{a}\right)$ values of $0.16 \mu \mathrm{m}$ and $0.02 \mu \mathrm{m}$, respectively. The parameter $R_{a}$ was determined using a Surftest SS measuring system, with the same scanning area for all samples. The maghemite $\left(\gamma-\mathrm{Fe}_{2} \mathrm{O}_{3}\right)$ nanoparticles used were synthesized following Massart's method (Massart [34]) through the precipitation of $\mathrm{Fe}^{2+}$ and $\mathrm{Fe}^{3+}$ salts in alkaline medium and dispersed in water.

The deposition of maghemite $\left(\gamma-\mathrm{Fe}_{2} \mathrm{O}_{3}\right)$ on the heating surface was carried out by evaporation with a nanoparticle suspension consisting of distilled water and maghemite nanoparticles with $10 \mathrm{~nm}$ or $80 \mathrm{~nm}$ diameter. It is important to note that this procedure is similar to that used by Heitch et al. [20] and Souza et al. [27]. The nanostructured

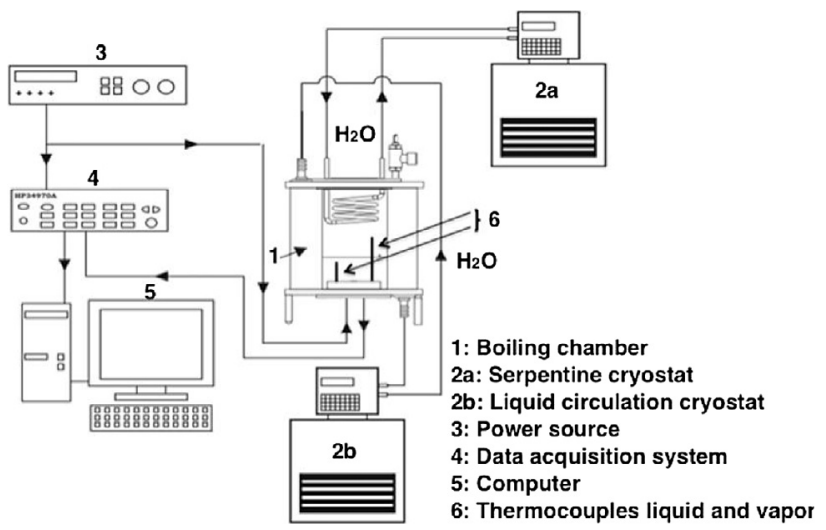

Fig. 1. Schematic drawing of the experimental apparatus. 


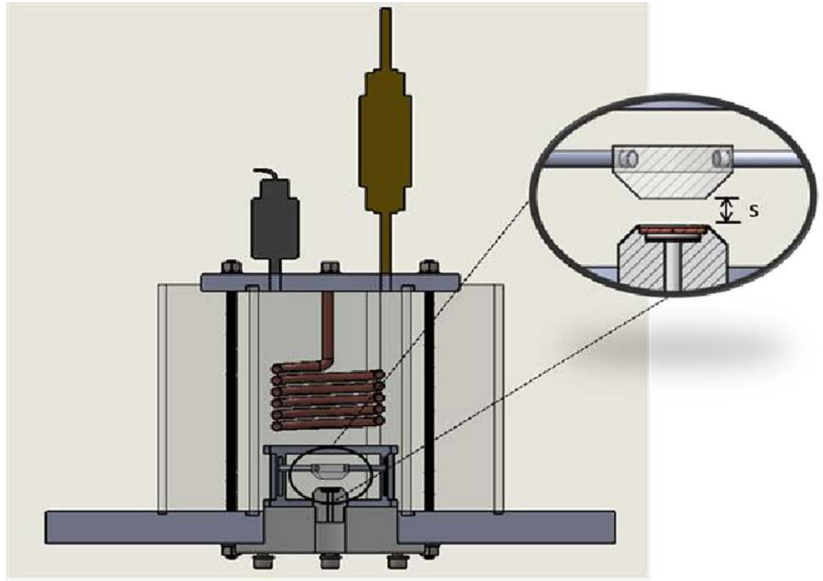

(a)
Fig. 2. Scheme of the boiling chamber. (a) Test section and confining element are shown in detail in the inset and (b) thermocouples location in the copper disc. surfaces were prepared with the same volumetric concentration of $0.29 \mathrm{~g} / \mathrm{l}$ at $\mathrm{pH}=2$. In each case, a layer of suspension was firstly deposited onto the copper disc using a syringe. The surface is connected to a power source, which allows surface heating and consequent evaporation of the base fluid, leaving only the deposited nanoparticles.

\subsection{Characterization of samples}

The characterization of the samples was carried out at the Materials Laboratory (LabMat) at the Federal University of Santa Catarina, Brazil, using the following techniques: scanning electron microscopy (SEM) to obtain structural and chemical information; the Surftest SS 401 model to obtain the average roughness $\left(R_{a}\right)$ for each surface; and a goniometry OCA 20 from Dataphysics Company to measure the apparent static $(\theta)$, and advancing $\left(\theta_{a}\right)$ and receding $\left(\theta_{r}\right)$ contact angles. All samples showed complete wettability, thus, it was not possible to observe the contact angle hysteresis. This behavior was expected because HFE 7100 has a low surface tension value (around $0.013 \mathrm{~N} / \mathrm{m}$ ), i.e., it is a wellwetting fluid.

\subsection{Visualization of the boiling process}

A visualization of the boiling process (lateral view), was obtained with a high speed $\mathrm{PCO}^{\circledR}$ camera, that captures 640 frames per second at the best resolution $(1024 \times 1024)$. A special lighting distribution was applied using small LED lamps placed in front of the boiling chamber and at the opposite side of it [35].

\section{Results}

\subsection{Results for unconfined case}

Two schemes for the mechanisms that characterize different regions of the nanostructured surface are presented in this section. Souza et al. [27] observed an increase of around 55\% in the HTC for a nanostructured surface with the deposition of nanoparticles of $10 \mathrm{~nm}$ diameter compared to the case where the surface was without deposition. However, for the surface nanostructured with nanoparticles of $80 \mathrm{~nm}$ diameter a $29 \%$ decrease in the HTC was observed. This behavior could be explained by considering a combination of different mechanisms, as shown in Fig. 3.

Fig. 3 provides a scheme showing the different mechanisms acting on three different regions, as follows:

Region I: a plain surface with nanoparticle deposition that leads to an increase in the nucleation site density. In this region, even when the nanoparticle deposition on the surface is not uniform, for example, with clusters, the porous surface provides a large amount of nucleation sites.

Region II: in this region the nanoparticle deposition diminishes the cavity radius, leading to an increase in the capillary effect ( $\mathrm{Ji}$ et al. [25]). A small pore size yields a large capillary pressure, resulting in a large liquid supply capability.

Region III: region characterized by nucleation sites with a larger pore size, which contribute to a low liquid flow resistance. The nanoparticles are sitting in the nucleation sites and multiplying them by splitting a single nucleation site into multiple ones.

The decrease in the HTC for the case with the deposition of larger nanoparticles could be explained by two effects: greater thermal resistance to boiling due to the thicker layer of nanoparticles and a reduced number of active sites due to the blocking of some sites. The scheme in Fig. 4 exemplifies this phenomenon.

In this case, the boiling mechanisms can be classified into the following regions:

Region I: a plain surface area with the deposition of nanoparticles. Due to a thicker nanoparticle layer, the thermal resistance to boiling will be higher than in the case without nanoparticle deposition.

Region II: in this region the nanoparticles sit in the nucleation sites and can block them, inhibiting the nucleation, causing a decrease in the active site density and, consequently, a decrease in the heat transfer coefficient.

Region III: In this region a higher degree of superheating may be required to obtain active nucleation sites.

Some researchers [26] defend the idea that when the nanoparticle concentration is over a critical value, a thin nanoparticle film is formed on the surface, resulting in a reduction in both the effective surface area and the number of active cavities. However, as reported in [27], for the same nanoparticle concentration it is possible to observe an increase or a decreasing in the HTC depending on the ratio between the roughness of the surface and the nanoparticle size, represented by the parameter SIP [24].

Fig. 5 shows the experimental results for the unconfined case and for smooth surfaces tested with the deposition of maghemite nanoparticles of 10 and $80 \mathrm{~nm}$ diameter (SS-NP10 and SS-NP80) and without deposition (SS), for which the roughness value is $0.02 \mu \mathrm{m}$ (Table 1 ). In this case, the HTC decreases for both nanoparticle diameters, with the largest decrease observed for the deposition of smaller nanoparticles (SS-NP10), that is, around $37 \%$ for $q ">50 \mathrm{~kW} / \mathrm{m}^{2}$. This behavior could be better interpreted considering the value of the parameter SIP. For the smooth surface with the deposition of nanoparticles of $10 \mathrm{~nm}$ diameter (SS-NP10), the ratio between the surface roughness and the particle size is close to unity. Thus, the nanoparticles block the active nucleation sites and the boiling performance reaches the minimum value. Although this behavior is also observed for the rough surface, with the 
Table 1

Description of the heating surfaces tested in this study and in Souza et al. [27].

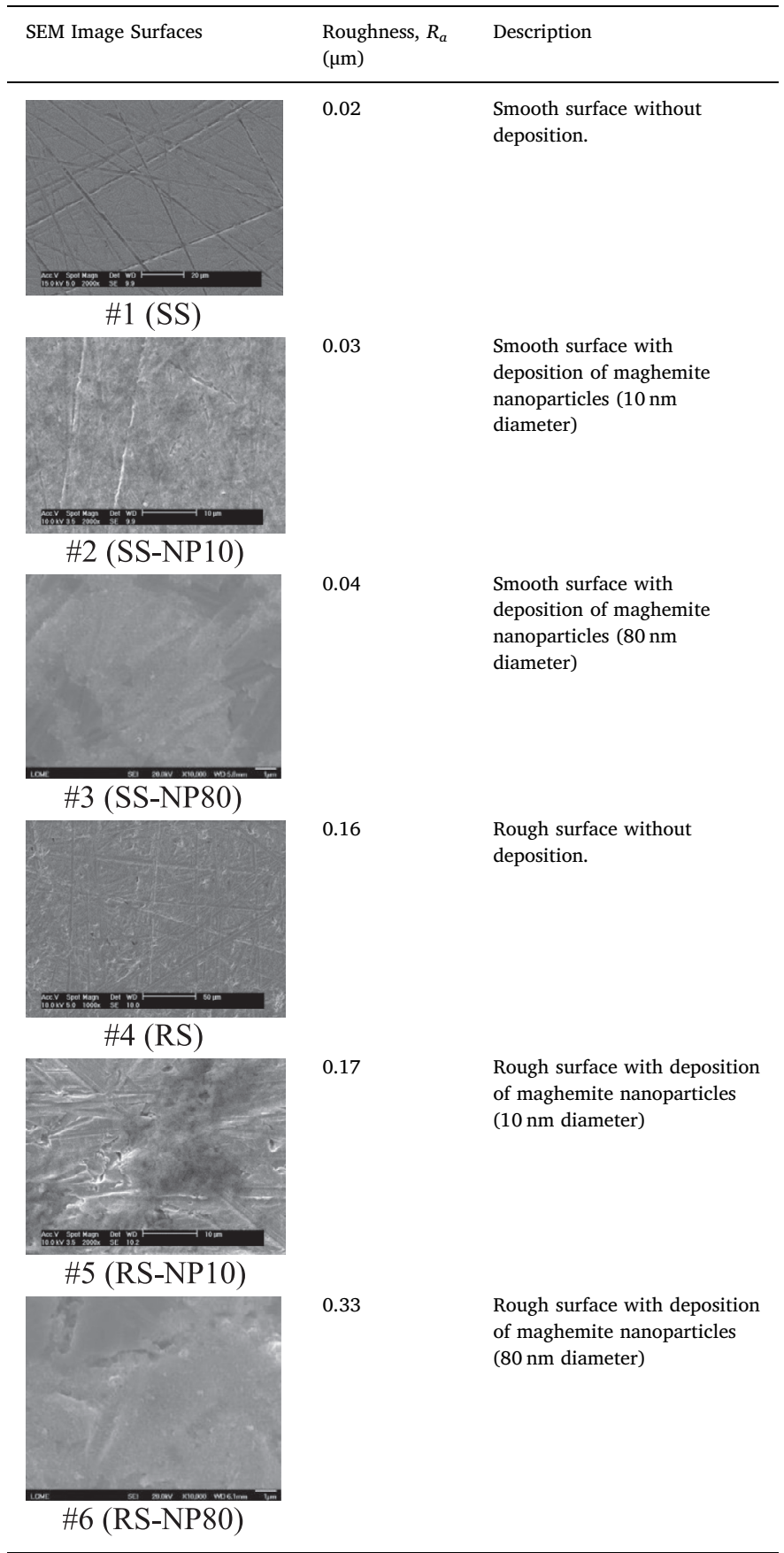

Small pore size

Increase in the capillary effect

Gas trapping

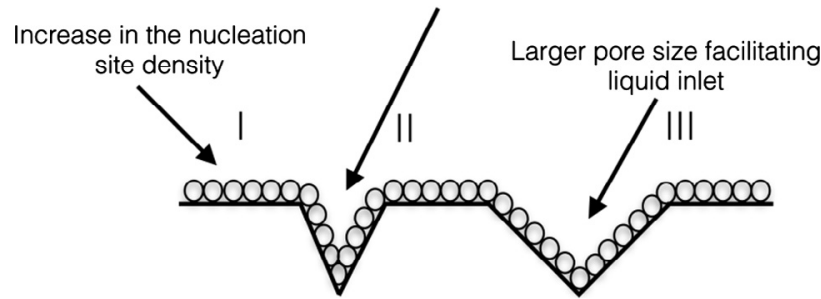

Fig. 3. Scheme to represent the different mechanisms acting on a rough surface with deposition of nanoparticles of $10 \mathrm{~nm}$ diameter.
Blockage of the

nucleation sites

Increase in the thermal resistance

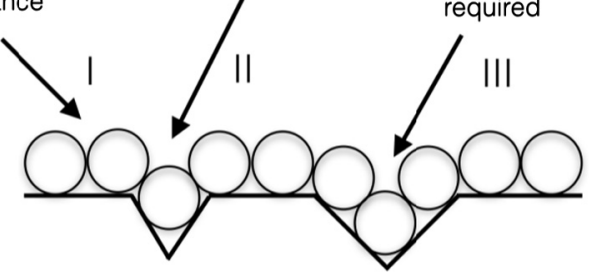

Fig. 4. Scheme showing the deposition of nanoparticles of $80 \mathrm{~nm}$ diameter on a rough surface.

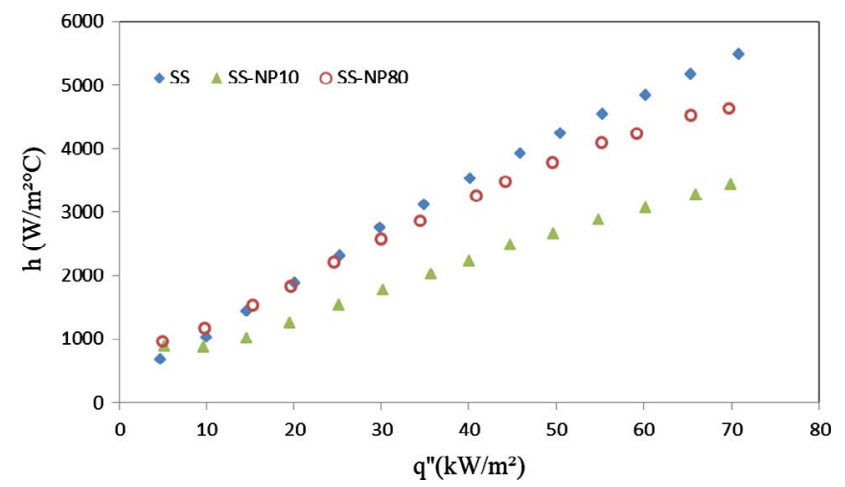

Fig. 5. Heat transfer coefficient, for unconfined case, as a function of heat flux for SSNP10, SS-NP80 and SS

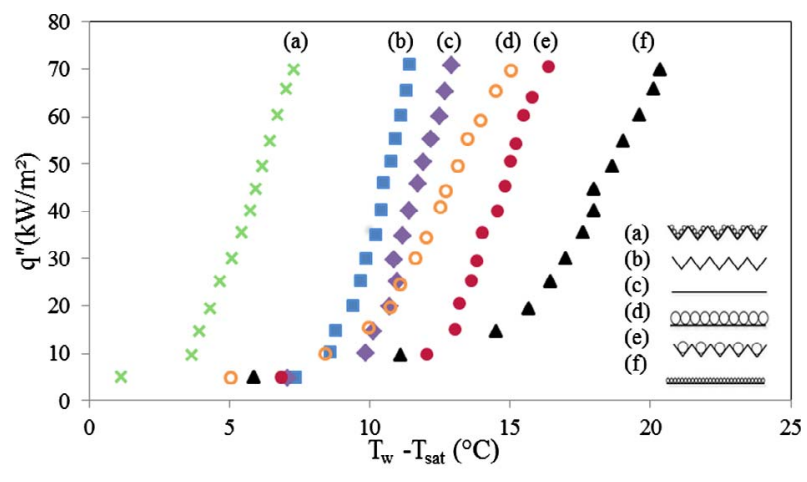

$\times$ RS-NP10 $\because \mathrm{RS} \quad \bullet \mathrm{SS} \quad \mathrm{SS}-\mathrm{NP} 80 \quad \bullet \mathrm{RS}-\mathrm{NP} 80 \quad \Delta \mathrm{SS}-\mathrm{NP} 10$

Fig. 6. Boiling curves for unconfined case and for SS, RS, RS-NP10, RS-NP80, SS-NP10, and SS-NP80 ((a), (b) and (e) data points from [1]).

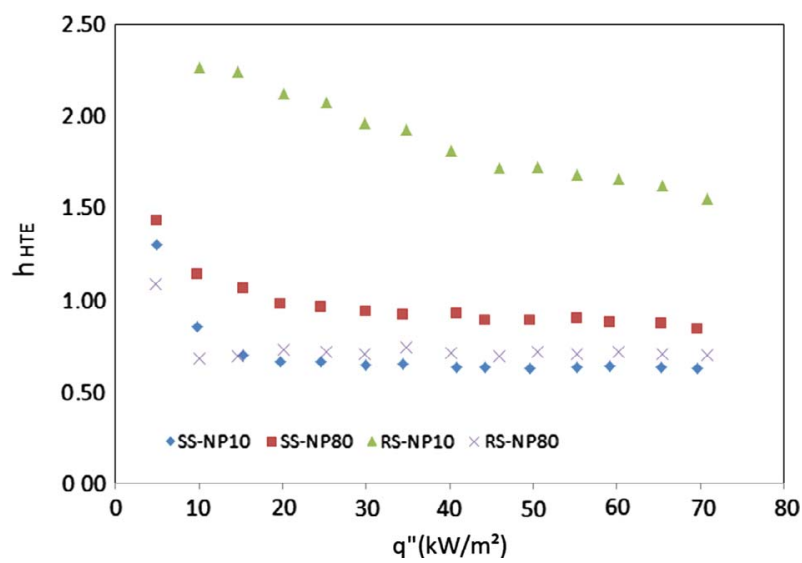

Fig. 7. Heat transfer enhancement ratio as a function of heat flux, for the smooth and rough surfaces and for unconfined case. 


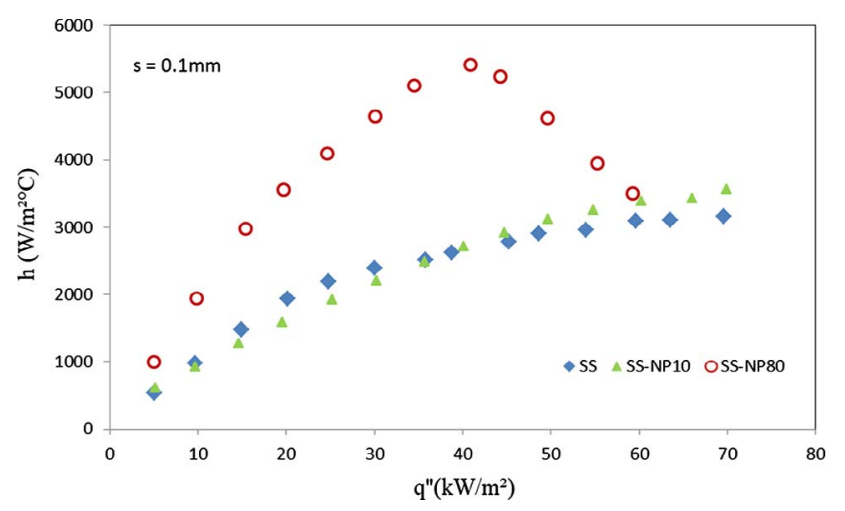

Fig. 8. Comparison between heated smooth surface without deposition and maghemitenanostructured surfaces with $10 \mathrm{~nm}$ and $80 \mathrm{~nm}$ diameter, for the confined case.

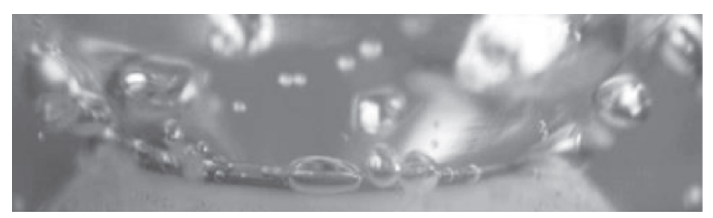

(a) SS

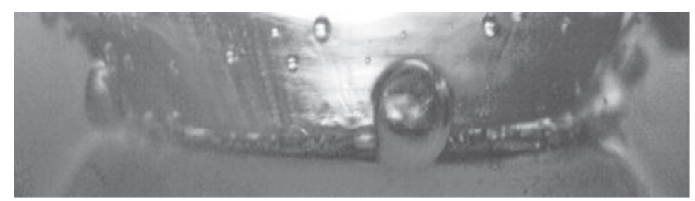

(b) SS-NP10

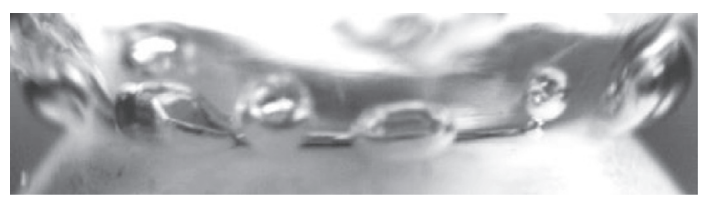

(c) SS-NP80

Fig. 9. Lateral views of the boiling process for smooth surfaces and for $q^{\prime \prime}=40 \mathrm{~kW} / \mathrm{m}^{2}$, for the confined case.

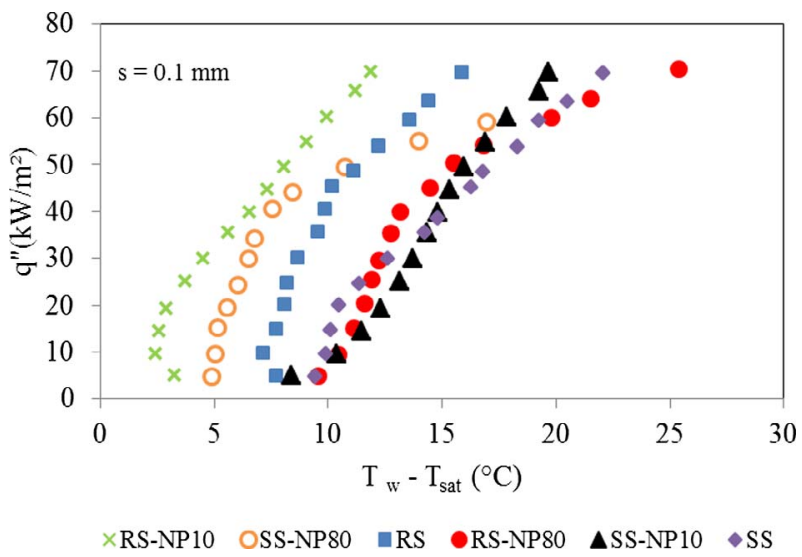

Fig. 10. Boiling curves for confined case and for SS, RS, RS-NP10, RS-NP80, SS-NP10, and SS-NP80.

deposition of nanoparticles of $80 \mathrm{~nm}$ diameter (RS-NP80), its effect is weaker because the nanoparticles are too small to block the nucleation sites completely.

Fig. 6 gives the boiling curves for the unconfined case and for all surfaces tested in this study, and the previous results reported in [27] are also plotted, the latter being represented by the experimental data of curves (a), (b) and (e).

Narayan et al. [24] observed an increase in the HTC when the average particle size was much lower than the surface roughness, as shown in this study for RS-NP10. According to the authors, when the ratio between the surface roughness, $R_{a}$, and the particle size, $d_{p}$, is much higher than unity (in their study this ratio was equal to 10.4) the enhancement in the heat transfer is greater. This behavior can be observed in Fig. 9. The highest HTC occurs for the case where the ratio between the surface roughness and nanoparticle diameter is 16 .

In order to show more clearly the effect of the interaction between nanoparticle deposition and the surface roughness on the enhancement/deterioration of the HTC, the experimental results for unconfined case were evaluated using the heat transfer enhancement ratio $\left(\mathrm{h}_{\mathrm{HTE}}\right)$, given by

$h_{H T E}=\frac{h_{\text {coated }}}{h_{\text {uncoated }}}$

where $h_{\text {coated }}$ is the heat transfer coefficient of the nanocoated surfaces, and $h_{\text {uncoated }}$ is the HTC of the uncoated surfaces (smooth - SS and rough - RS surfaces). In Fig. 7, the $h_{\text {HTE }}$ behavior has the same trend presented in the Fig. 6, i.e., the HTC increases as the surface interaction parameter (SIP) is higher than 1.

In summary, the HTC varies considerably with the relation between surface roughness and nanoparticles size deposited on the heating surface, as follows:

For rough surfaces: the heat transfer increases with the surface deposition of smaller nanoparticles (55\%) and decreases for the surface deposition of greater nanoparticles (29\%).

For smooth surfaces: the heat transfer decreases for both nanoparticle sizes deposited on the heating surface, being highest for the nanoparticles with the smaller diameter (37\%).

\subsection{Results for confined case}

An enhancement in the HTC of around 145\% was observed by Souza et al. [27] for heat fluxes lower than $30 \mathrm{~kW} / \mathrm{m}^{2}$ and for a heated surface with the deposition of maghemite nanoparticles of $10 \mathrm{~nm}$ diameter over a rough surface with $R_{a}=0.16 \mu \mathrm{m}$. This could be explained by an increase in the number of active nucleation sites on the surface. The residence time of the vapor bubbles in the gap promotes the coalescence and deformation of the vapor bubbles, leading to the evaporation of a thin liquid film, present between the heated surface and the base of the deformed bubble. However, as the heat flux increases the vapor bubbles grow rapidly on the heating surface, creating a mass of vapor, which inhibits the cooling effect and initiates the dryout phenomenon.

Due to the technical limitations of the heating system, only the beginning of dryout heat flux for the confined case was obtained.

Fig. 8 shows the effect of gap size on the HTC, for smooth surfaces with and without nanoparticle deposition. In this case, the surface with the deposition of larger nanoparticles showed different behavior, depending on the heat flux value: for $q^{\prime \prime}<40 \mathrm{~kW} / \mathrm{m}^{2}$, an increase in the heat transfer was observed, whereas for heat fluxes higher than this value a decrease in the HTC occurred, indicating the beginning of dryout.

The authors suggest that the mechanism responsible for the high HTC, for the smooth surface with the deposition of nanoparticles of $80 \mathrm{~nm}$ diameter, could be an increase in the surface area of a liquid film.

It is interesting to compare the results shown in Figs. 5 and 8. When boiling occurred under confinement, there was enhancement of the heat transfer coefficient for the two nanostructured surfaces. For example, with a heat flux of $40 \mathrm{~kW} / \mathrm{m}^{2}$, the HTC for the surface with the deposition of nanoparticles of $10 \mathrm{~nm}$ of diameter (SIP $=3$ ) increased by $31 \%$, from 2100 to $2750 \mathrm{~kW} / \mathrm{m}^{2}{ }^{\circ} \mathrm{C}$, and for the deposition of nanoparticles of $80 \mathrm{~nm}(\mathrm{SIP}=0.5)$ this value increased by $100 \%$, from 3400 to $5500 \mathrm{~kW} / \mathrm{m}^{2}{ }^{\circ} \mathrm{C}$. However, for the cases without deposition, the HTC 
decreased by $21 \%$, from 3500 to $2750 \mathrm{~kW} / \mathrm{m}^{2}{ }^{\circ} \mathrm{C}$. These results also demonstrate that the parameter SIP is not suitable for the interpretation of the experimental results for confined boiling.

The use of a high-speed camera aids in understanding the effect of the gap size on the three smooth surfaces tested (see Fig. 9a-c). The smooth surface presents smaller nucleation sites due to the lower roughness. In this case, when the nucleation sites are activated the vapor bubble diameter is reduced and the effect of the gap size is minimal. This is because the coalescence of the vapor bubbles is not intensified, as can be seen in Fig. 9b. It is important to note that the average surface roughness is of the same magnitude as the smaller nanoparticle diameter. Therefore, the deposition of nanoparticles on the heating surface blocks the majority of nucleation sites, hindering the growth of the vapor bubbles and the coalescence effect.

Also, in Fig. 9c, it is possible to note that the effect of the gap size is important due the fact that the surface roughness is smaller than the nanoparticle size. In this case, coalesced bubbles are seen leaving the channel, and after the departure of a coalesced bubble a front of cold liquid enters in the gap and cools the surface, increasing the heat transfer to $q^{\prime \prime}=45 \mathrm{~kW} / \mathrm{m}^{2}$. Furthermore, the intensification of the heat transfer for SS-NP80 can be explained by an increase in the area covered by the liquid film together with an intensification of the vaporization in the meniscus formed between nanoparticles of greater diameter and the smooth heating surface.

Fig. 10 shows the boiling curves for the confined case and for all surfaces tested in this study, and allows a comparison with the results obtained by [27]. For RS-NP10, SS-NP80 and RS, the experimental points are shifted to the left compared with the other cases, characterizing an enhancement in the heat transfer. For these surfaces, the effect of the gap size is important, as explained earlier.

The decrease in the heat transfer coefficient for SS, RS-NP80 and SSNP10 shows that these surfaces have less active nucleation sites and a higher thermal resistance to boiling.

\section{Conclusions}

An experimental analysis of the confined and unconfined nucleate boiling of saturated HFE7100, for surfaces with different roughness values and the deposition of nanoparticles with different sizes (but with the same volumetric concentration, $0.29 \mathrm{~g} / \mathrm{l}$ ), was carried out. The main conclusions are:

The HTC is dependent on the ratio between the surface roughness $\left(R_{a}\right)$ and the nanoparticle diameter, that is, the parameter SIP introduced by Narayan et al. [24], rather than directly on these two variables considered individually. This is attributed to the interaction of different effects: an increase in the nucleation site density, a decrease in the cavity radius leading to an increase in the capillary effect and a lower thermal resistance.

The decrease in the HTC for the nanostructured cases and for surfaces with an SIP close to 1 is around $37 \%$. This behavior can be explained by the blockage of nucleation sites and the need for a greater degree of superheating in order to activate the nucleation sites.

For confined boiling, with $s=0.1 \mathrm{~mm}$, the heat transfer coefficient increases by $100 \%$ for heat flux values close to $40 \mathrm{~kW} / \mathrm{m}^{2}$ and for a smooth surface $\left(R_{a}=0.02 \mu \mathrm{m}\right)$ with the deposition of maghemite nanoparticles of $80 \mathrm{~nm}$ diameter. However, this enhancement is cancelled for higher heat fluxes, such as $60 \mathrm{~kW} / \mathrm{m}^{2}$. For heat flux values higher than $40 \mathrm{~kW} / \mathrm{m}^{2}$, there is a decrease in the HTC due to the creation of a large mass of vapor that inhibits the cooling effect in the gap, leading to the development of the dryout phenomenon.

The effect of confinement in the case of the smooth surface, at a heat flux of $40 \mathrm{~kW} / \mathrm{m}^{2}$, on the boiling HTC was increases of $31 \%$ and $100 \%$ for the cases with the deposition of nanoparticles of $10 \mathrm{~nm}$ and $80 \mathrm{~nm}$, respectively. However, for the cases without deposition the HTC decreased by $21 \%$. To the best of our knowledge, these results are published for the first time herein. The smooth surface presents smaller nucleation sites and when these are activated the vapor bubble diameter is reduced and the effect of the gap size is minimal.

For the smooth surface with the deposition of nanoparticles of $80 \mathrm{~nm}, R_{a} \ll d_{p}$ and there are coalesced bubbles leaving the channel. Thus, after the departure of a coalesced bubble a front of cold liquid enters in the channel and cools the surface, improving the heat transfer. Furthermore, the intensification of the heat transfer in this case could be explained by an increase in the area covered by the liquid film added and the intensification of vaporization in the meniscus formed between nanoparticles of greater diameter and the smooth heating surface.

The nanoparticle adhesion on the heating surface plays a more important role in the confined boiling process that the surface roughness.

\section{Acknowledgments}

The authors gratefully acknowledge the support of Coordination for the Improvement of Higher Education Personnel - CAPES (PROENG and NANOBIOTEC Projects), National Counsel of Technological and Scientific Development of Brazil - CNPq, and Prof. Maria de Fátima da Silva and Mr. Marcelo Parise from NFA/Instituto de Física/ Universidade de Brasília for supplying the nanofluids. The authors also extend their gratitude to Mr. André Oliveira for his important contribution to the laboratory work.

\section{References}

[1] C.H. Wang, V.K. Dhir, Effect of surface wettability on active nucleation site density during pool boiling of water on a vertical surface, J. Heat Transfer 115 (1993) 659-669.

[2] B.B. Mikic, W.M. Rohsenow, A new correlation of pool boiling data including the effect of heating surface characteristics, Trans. ASME, J. Heat Transfer 91 (1969) $245-250$.

[3] P.J. Berenson, Experiments on pool boiling heat transfer, Int. J. Heat Mass Transfer 5 (1962) 985-999.

[4] M.G. Kang, Effect of surface roughness on pool boiling heat transfer, Int. J. Heat Mass Transfer 43 (2000) 4073-4085.

[5] V.K. Dhir, Boiling heat transfer, Annu. Rev. Fluid Mech. 30 (1998) 365-401.

[6] B.J. Jones, J.P. McHale, S.V. Garimella, The influence of surface roughness on nucleate pool boiling heat transfer, J. Heat Transfer 131 (12) (2009) 121009.

[7] G. Wallis, One Dimensional Two-Phase Flow, McGraw-Hill Inc., 1969.

[8] B. Mehta, S. Khandekar, Two-phase closed thermosyphon with nanofluids, in: 14th International Heat Pipe Conference (14th IHPC), Florianópolis, SC, Brazil, April 22-27, 2007.

[9] J.P. McHale, S.V. Garimella, Bubble nucleation characteristics in pool boiling of a wetting liquid on smooth and rough surfaces, Int. J. Multiphase Flow 36 (2010) 249-260.

[10] V.K. Dhir, Phase change heat transfer-a perspective for the future, in: Rohsenow Symposium, Massachusetts Institute of Technology, 2003.

[11] C.T. Avedisian, Phase change heat transfer - a perspective for the Future: Response to Professor K. Dhir. Rohsenow Symposium., Massachusetts Institute of Technology, 2003. (http://web.mit.edu/hmtl/www/rohsenowsymposium.html).

[12] D. Wen, Influence of nanoparticles on boiling heat transfer, Appl. Therm. Eng. 41 (2012) 2-9.

[13] Z. Shahmoradi, N. Etesam, M.N. Esfahany, Pool boiling characteristics of nanofluid on flat plate based on heater surface analysis, Int. Commun. Heat Mass Transfer 47 (2013) 113-120.

[14] A. Rainho Neto, J.L.G. Oliveira, J.C. Passos, Heat transfer coefficient and critical heat flux during nucleate pool boiling of water in the presence of nanoparticles of alumina, maghemite and CNTs, Appl. Therm. Eng. 111 (2017) 1493-1506.

[15] H.D. Kim, M.H. Kim, Effect of nanoparticle deposition on capillary wicking that influences the critical heat flux in nanofluids, Appl. Phys. Lett. 91 (2007).

[16] I.C. Bang, S.H. Chang, Boiling heat transfer performance and phenomena of $\mathrm{Al}_{2} \mathrm{O}_{3}-$ water nanofluids from a plain surface in a pool, Int. J. Heat Mass Transfer 48 (2005) 2407-2419.

[17] S.M. Kwark, M.Amaya, S.M. You, Pool Boiling heat transfer characteristics of nanocoating in various working fluids, in: 27th IEEE SEMI-THERM Symposium, San Jose, CA USA, 2011, pp. 146-154.

[18] M.A. Kedzierski, Effect of $\mathrm{CuO}$ nanoparticle concentration on R134a/lubricant poolboiling heat transfer, J. Heat Transfer-Trans. ASME 131 (2009).

[19] S.B. White, A.J. Shih, K.P. Pipe, Effects of nanoparticle layering on nanofluid and base fluid pool boiling heat transfer from a horizontal surface under atmospheric pressure, J. Appl. Phys. 107 (2010) 114302.

[20] L.V. Heitich, J.C. Passos, E.M. Cardoso, M.F. da Silva, A.N. Klein, Nucleate boiling of water using nanostructured surfaces, J. Brazilian Soc. Mech. Sci. Eng. 36 (2014) 181-192.

[21] S. Jun, S. Sinha-Ray, A.L. Yarin, Pool boiling on nano-textured surfaces, 
International Journal of Heat and Mass Transfer 62 (2013) 99-111.

[22] Y. Tang, Li.Q. Tang, J. Qing, L. Lu, K. Chen, Pool-boiling enhancement by novel metallic nanoporous surface, Exp. Therm. Fluid Sci. 44 (2013) 194-198.

[23] J.H. Lee, T. Lee, Y.H. Jeong, The effect of pressure on the critical heat flux in waterbased nanofluids containing $\mathrm{Al}_{2} \mathrm{O}_{3}$ and $\mathrm{Fe}_{3} \mathrm{O}_{4}$ nanoparticles, Int. J. Heat Mass Transfer 61 (2013) 432-438.

[24] G.P. Narayan, K.B. Anoop, S.K. Das, Mechanism of enhancement/deterioration of boiling heat transfer using stable nanoparticle suspensions over vertical tubes, J. Appl. Phys. 102 (7) (2007) 074317.

[25] X. Ji, J. Xu, Z. Zhao, W. Yang, Pool boiling heat transfer on uniform and nonuniform porous coating surfaces, Exp. Therm. Fluid Sci. 48 (2013) 198-212.

[26] E.S. Kim, J.Y. Jung, Y.T. Kang, The effect of surface area on pool boiling heat transfer coefficient and CHF of $\mathrm{A}_{1} 2_{\mathrm{O}} 3$ /water nanofluids, J. Mech. Sci. Technol. 27 (10) (2013) 3177-3182

[27] R.R. Souza, J.C. Passos, E.M. Cardoso, Influence of nanoparticle size and gap size on nucleate boiling using HFE7100, Exp. Therm. Fluid Sci. 59 (2014) 195-201.

[28] E. Ishibashi, K. Nishikawa, Saturated boiling heat transfer in narrow spaces, Int. J. Heat Mass Transfer 12 (1969) 863-866.

[29] Y. Katto, S. Yokoya, K. Teraoka, Nucleate and transition boiling in a narrow space between two horizontal parallel disk-surface, Bull. JSME 20 (143) (1977) 638-643. [30] J.C. Passos, F.R. Hirata, L.F.B. Possamai, M. Balsamo, M. Misale, Confined boiling of FC72 and FC87 on a downward facing heating copper disk, Int. J. Heat Fluid Flow 25 (2) (2004) 313-319.

[31] E.M. Cardoso, J.C. Passos, Nucleate boiling of n-pentane in a horizontal confined space, Heat Transfer Eng. 34 (2013) 470-478, http://dx.doi.org/10.1080/ 01457632.2012 .722438$.

[32] E.M. Cardoso, O. Kannengieser, B. Stutz, J.C. Passos, FC72 and FC87 nucleate boiling inside a narrow horizontal space, Exp. Therm. Fluid Sci. 35 (2011) 1038-1045.

[33] C.Y. Yang, C.F. Liu, Effect of coating layer thickness for boiling heat transfer on micro porous coated surface in confined and unconfined spaces, Exp. Therm. Fluid Sci. 47 (2013) 40-47.

[34] R. Massart, Magnetic fluids and process for obtain them, US Patent 4329241, 1982.

[35] R.R. Souza, Analysis of the of the heat transfer during the confined nucleate boiling of the HFE 7100 using nanostructured surfaces, PhD thesis, in Portuguese, Federal University of Santa Catarina, Graduate Program on Mechanical Engineering, Florianopolis, SC, Brazil, 2014. 